\title{
BMJ Open Lifestyle factors associated with incidence of rheumatoid arthritis in US adults: analysis of National Health and Nutrition Examination Survey database and meta-analysis
}

Ding Ye (1) , ${ }^{1}$ Yingying Mao, ${ }^{1}$ Yang Xu, ${ }^{1}$ Xueli Xu, ${ }^{1}$ Zhijun Xie, ${ }^{2}$ Chengping Wen ${ }^{2}$

To cite: Ye D, Mao Y, Xu Y, et al. Lifestyle factors associated with incidence of rheumatoid arthritis in US adults: analysis of National Health and Nutrition Examination Survey database and meta-analysis. BMJ Open 2021;11:e038137. doi:10.1136/ bmjopen-2020-038137

- Prepublication history and additional material for this paper is available online. To view these files, please visit the journal online (http://dx.doi.org/10. 1136/bmjopen-2020-038137).

Received 28 February 2020 Revised 29 0ctober 2020 Accepted 06 November 2020

Check for updates

(C) Author(s) (or their employer(s)) 2021. Re-use permitted under CC BY-NC. No commercial re-use. See rights and permissions. Published by BMJ.

${ }^{1}$ Department of Epidemiology and Biostatistics, College of Basic Medical Sciences, Zhejiang Chinese Medical University, Hangzhou, Zhejiang, China

${ }^{2}$ Institute of Basic Research in Clinical Medicine, College of Basic Medical Sciences, Zhejiang Chinese Medical University, Hangzhou, Zhejiang, China

Correspondence to Dr Chengping Wen; wengcp@163.com

\section{ABSTRACT}

Objective To quantify rheumatoid arthritis (RA) cases attributable to selected non-genetic risk factors.

Design National Health and Nutrition Examination Survey (NHANES) and meta-analysis.

Participants US adults.

Data sources The prevalence of exposure was obtained from NHANES. Weighted analysis was performed to account for the complex sampling design in NHANES. PubMed and Web of Science up to 31 March 2019 were searched to identify epidemiological studies reported the association between non-genetic risk factors and RA in US adults. Relative risk (RR) value and the corresponding $\mathrm{Cl}$ were pooled by meta-analysis to evaluate the associations between modifiable risk factors and RA. Population attributable fraction (PAF) was calculated based on the prevalence and RR data.

Results The weighted percentages of former smokers, current smokers and overweight or obese people were $24.84 \%, 23.93 \%$ and $63.97 \%$, and the average alcohol consumption was $51.34 \mathrm{~g} /$ week. In the meta-analysis, we found that former smokers (RR 1.22, 95\% Cl 1.10 to 1.36) and current smokers (RR $1.47,95 \% \mathrm{Cl} 1.29$ to 1.68) had higher risks of RA. Overweight and obese individuals had 1.27-fold (95\% $\mathrm{Cl} 1.09$ to 1.48) increased risk of RA. Each per $50 \mathrm{~g} /$ week increment of alcohol consumption was associated with $8 \%(95 \% \mathrm{Cl} 0 \%$ to $16 \%)$ reduction in the risk of RA. Therefore, PAF value of smoking was $14.00 \%$ (95\% Cl $8.13 \%$ to $23.33 \%$ ). Excess body mass index (BMI) was found to account for $14.73 \%(95 \% \mathrm{Cl}$ $5.45 \%$ to $23.50 \%$ ) of RA incidence. The fraction of RA risk attributed by low alcohol intake was $8.21 \%$ (95\% Cl 0.31\% to $16.39 \%)$. Collectively, we found that $32.69 \%(95 \%$ $\mathrm{Cl} 13.41 \%$ to $50.96 \%$ ) of RA cases were attributable to smoking, overweight or obesity and low alcohol drinking. Conclusion Nearly $33 \%$ of RA incidence was attributed to smoking, excess BMI and low alcohol drinking in USA. Our findings could provide a basis for developing guidelines of RA prevention and control in USA.

\section{BACKGROUND}

Rheumatoid arthritis (RA) is a systemic disease that causes progressive articular destruction and associated comorbidities in
Strengths and limitations of this study

- This study is the first to comprehensively evaluate the burden of rheumatoid arthritis (RA) incidence attributable to well-known risk factors among US adults.

- Population attributable fraction estimation was based on the prevalence from National Health and Nutrition Examination Survey database and relative risk value by meta-analysis, which ensures data quality and scale.

- Limitations of this study included that several other known risk factors of RA exist but have not been included in our study.

vascular, metabolic, bone and psychological domains. ${ }^{1}$ RA affects at least twice as many women as men, and although it can occur at any age, the peak incidence is at the age of 50 years. ${ }^{2}$ Incidence varies considerably in different regions and published work suggests that North American and North European countries have higher median incidence rates than South European countries. ${ }^{3}$

$\mathrm{RA}$ is considered to be a multifactorial disease, resulting from the interaction of both genetic and environmental factors. ${ }^{4}$ Multiple lifestyle and dietary risks factors have been found to be associated with RA. ${ }^{5-8}$ One of the ways in which individuals may respond to an environmental exposure is through changes in their epigenome to have a profound effect on gene expression, such as post-translational histone modifications and DNA methylation, to influence the risk of RA. ${ }^{9}$ The weight of risk factors to the burden of RA in a given population is critical for better understanding of the relative importance of risk factors and for prioritisation of public health efforts.

The population attributable fraction (PAF) is an epidemiological measure widely used 
to assess the public health impact of certain risk factors in populations. ${ }^{10}$ Several studies illustrate preventive measures will have distinct effects on the societal and on the individual level. For example, evidence in Sweden showed that smoking seems to be responsible for $20 \%$ of all RA, 35\% of all antibodies to citrullinated protein antigen-positive RA and for $55 \%$ of all cases of RA in individuals carrying double HLA-DRB1 SE alleles. ${ }^{11}$ The PAF calculation could also be generalised to the joint effects of two or more exposures, which is expected to be less than the sum of the PAF for each exposure, because individuals exposed to all of the exposures should not be counted multiple times. ${ }^{12}$ However, most of these studies were limited because they included only a single risk factor. Comprehensive evaluation of the burden of RA attributable to potentially modifiable risk factors is essential in prioritising resources and planning preventive measures against RA.

It should be noted that there may be ethnic and geographical variations in the association of each risk factor with RA. However, no systematic assessment of the preventable risk factors on RA is available for USA so far. Therefore, this study aimed to estimate the numbers and proportions of RA incidence among US adults that could be attributable to the documented risk factors. It also provides the opportunity to evaluate the potential to draw together preventative health messages for RA.

\section{METHODS}

\section{RA incidence data}

Estimated deaths and mortality by RA in USA in 2016 was obtained from WHO Global Health Estimates (GHE) project. ${ }^{13}$ GHE 2016 presents results for 183 WHO Member States, encompassing all those with a population of 90000 or greater in 2016, which confirms and expands previous $\mathrm{WHO}$ analyses of global health trends and improvements for years 2000-2016. The specific data sources and methods are described in the website. ${ }^{14}$ Overall, 2.3 thousand people aged more than 15 years died with RA, and the total death rate of RA was 0.88 per 100000.

RA incidence data were estimated by applying incidence mortality rates (IMR) to the data on RA deaths. We obtained IMR from a meta-analysis involving a total of 11 longitudinal studies, which used Poisson regression to model IMR. ${ }^{15}$ The IMR value was calculated as follows: number of deaths at the end of the study divided by the product of the mean number of RA patients during the study multiplied by the mean patient follow-up. The pooled IMR was 2.0/100 after the year of 1983. Thus, the total number of RA cases was 114.8 thousand at an estimated incidence of 0.44 per 1000 among US adults.

\section{Selection of risk factors}

We included the convincing and probable risk factors in our study to estimate the joint effect on RA risk. The risk factors which met the following explicit criteria were included: (1) it was one of the 84 behavioural, environmental and occupational, and metabolic risks defined by Global Burden of Disease Study $2016^{16}$; (2) there was sufficient evidence on the presence and magnitude of likely causal associations with RA risk from systematic reviews and meta-analysis, or high-quality epidemiological studies and (3) data on risk factor exposure were available from representative surveys in USA.

Two independent investigators (Mao Y and Ye D) performed the literature search, and the risk factors included in our study were listed in table 1 .

\section{Prevalence of risk factors}

Prevalence of exposure data was extracted from nationally representative studies in USA. As the current health effects of risk factors are a result of the accumulative patterns of past exposure to the risk factors, we assumed an average latency time of 10 years for risk factors and RA. Thus, priority was given to prevalence data of exposure referring to around 2006. In addition, we also conducted a sensitivity analysis with respect to different lag-time.

Table 1 Exposure rate of risk factors among US adults

\begin{tabular}{|c|c|c|c|c|}
\hline \multirow[b]{2}{*}{ Risk factor } & \multicolumn{2}{|c|}{ Main analysis } & \multicolumn{2}{|c|}{ Sensitivity analysis } \\
\hline & Crude & Weighted (SE) & Crude & Weighted (SE) \\
\hline \multicolumn{5}{|l|}{ Smoking status (\%) } \\
\hline Former & 25.32 & $24.84(1.04)$ & 26.39 & $24.65(1.35)$ \\
\hline Current & 21.90 & $23.93(1.22)$ & 21.70 & $24.87(1.08)$ \\
\hline$<25.0$ & 53.63 & $36.03(1.30)$ & 55.43 & $37.79(0.70)$ \\
\hline 25.0-29.9 & 23.44 & $31.40(0.82)$ & 25.04 & $33.57(1.06)$ \\
\hline$\geq 30.0$ & 22.93 & $32.57(1.44)$ & 19.53 & $28.64(1.03)$ \\
\hline Alcohol consumption (g/week) & 44.63 & $51.34(2.75)$ & 58.63 & $59.79(2.50)$ \\
\hline
\end{tabular}

BMI, body mass index. 
Prevalence data analysed in this study were extracted from the National Health and Nutrition Examination Survey (NHANES), which used a complex, multistage, probability sampling design to collect nationally representative sample of civilian, non-institutionalised US population and had become a continuous programme since 1999. A stratified, multistage probability cluster process was employed as the sampling strategy. ${ }^{17}$ NHANES $2005-$ 2006 was used to estimate the prevalence of risk factors. For sensitivity analysis, we also calculated the exposure rate in other 2-year survey cycle.

Smoking status was defined as never, former and current smoker. ${ }^{18}$ Individuals who reported that they had never smoked or smoked less than 100 cigarettes during their lifetimes were classified as never smokers. Former smokers were defined as participants who smoked at least 100 cigarettes during their lifetimes and were not currently smoking at the time of the survey. Participants who reported smoking at least 100 cigarettes in their lifetimes and smoked either every day or some days at the time of the survey were classified as current smokers. ${ }^{19}$ Body mass index (BMI) was calculated as weight in kilograms divided by height in metres squared. Alcohol consumption was classified as never for those who reported $<12$ drinks ever. ${ }^{20}$

\section{Relative risk data}

To evaluate the relative risk (RR) of risk factors and RA in the US population, we conducted a systematic search through databases of PubMed and Web of Science up to 31 March 2019, and the search strategy was presented in online supplemental table 1 . We conducted a metaanalysis to pool the RRs of epidemiological studies which reported the association between the risk factors and risk of RA in US population. The studies that fulfilled the following criteria were included for meta-analysis: (1) the study design was cohort, case-control or nested case-control study conducted in US population; (2) RR, and the corresponding 95\% CIs should be provided or sufficient data to calculate them were reported; (3) if several reports were from the same study, only the one with largest sample size was included. Two authors (Xu $\mathrm{Y}$ and $\mathrm{Xu} \mathrm{X}$ ) extracted detailed information including first author, year of publication, study design, sample size, gender, age, category of each risk factor, RR and 95\% CI. We extracted RR estimates from the maximally adjusted model to reduce the risk of possible unmeasured confounding. In addition, estimates for an alternative comparison of the categories was calculated by the method of Hamling et al. ${ }^{21}$ Two researchers (Xu Y and $\mathrm{Xu} \mathrm{X}$ ) independently rated the quality of the included studies using the Newcastle-Ottawa Scale with scores ranging from 0 to 9 points. ${ }^{22}$ Studies with a quality score more than seven points were considered as high quality.

We calculated study specific slopes (linear trends) and 95\% CIs from the natural logs of the reported RRs and CIs across categories of BMI. ${ }^{23}$ We also pooled the categories with BMI more than 25 to evaluate the association between excess BMI and risk of RA for PAF estimation.

As different studies used different units to express alcohol intake, the conversion was performed using the method developed by Fedirko et $a l^{24}$ (one drink=12.5 g; one ounce $=28.35 \mathrm{~g}$ and $1 \mathrm{~mL}=0.8 \mathrm{~g}$ ). A dose-response analysis on the association between alcohol drinking and risk of RA was carried out using both linear and nonlinear models on the natural logarithm of the RR using the method by Orsini N. ${ }^{25}$ The midpoint of the categories was used in the dose-response analysis. When the highest category was open ended, the midpoint was calculated as 1.2 times its lower bound. ${ }^{26}$ Data fitting was based on restricted cubic spline models using the fixed percentiles $5 \%, 35 \%, 65 \%$ and $95 \%$ as knot locations.

\section{Population attributable fraction}

$\mathrm{PAF}$ is the proportion of RA in the total population that can be avoided by modifying or removing the exposure of certain risk factors. For protective factors, the PAF was calculated for the group without the exposure.

PAF can be calculated by the formula proposed by Levin, ${ }^{27}$ among which $\mathrm{P}$ is the prevalence of exposure in a population, such as overweight and obesity.

$$
\mathrm{PAF}=\frac{P \times(\mathrm{RR}-1)}{[P \times(\mathrm{RR}-1)]+1}
$$

For multicategorical variable in risk factors such as smoking, PAF was estimated by the following formula. ${ }^{28}$

$$
\mathrm{PAF}=\frac{\sum P_{i} \times\left(\mathrm{RR}_{i}-1\right)}{\sum P_{i} \times\left(\mathrm{RR}_{i}-1\right)+1}
$$

$\mathrm{RR}_{\mathrm{i}}$ was the $\mathrm{RR}$ at group $\mathrm{i}$, and $\mathrm{P}_{\mathrm{i}}$ was the prevalence of group.

For continuous variables in risk factors such as alcohol consumption (started at zero), PAF was obtained by multiplying the RR for unit exposure and the average exposure level (d), shown in the following formula, assuming a loglinear relationship between exposure and RA risk. ${ }^{29}$

$$
\mathrm{PAF}=\frac{\exp \left[\ln \left(\mathrm{RR}_{i}\right) \times d\right]-1}{\exp \left[\ln \left(\mathrm{RR}_{i}\right) \times d\right]}
$$

We calculated the fraction of new cases of individual RA attributable to selected risk factors by applying the combined PAF. It can be estimated by the following formula ${ }^{12}$ where $\mathrm{r}=$ individual risk factor and $\mathrm{N}$ is number of risk factors.

$$
\text { multiple } \mathrm{PAF}=1-\prod_{r=1}^{N}(1-P A F r)
$$

\section{Statistical analysis}

In the data analyses for prevalence of the risk factors in NHANES, the sampling weights for interview (WTMEC2YR) and study design variables (SDMVPSU and SDMVSTRA) were applied. Weighted analyses were conducted to consider the complex sampling design and to obtain appropriate SEs.

Summary RR was synthesised to evaluate the association between each risk factor and risk of RA. The heterogeneity among studies was assessed using the Cochran 
Table 2 Basic characteristic of included studies in the meta-analysis on the association between selected risk factors and RA

\begin{tabular}{|c|c|c|c|c|c|c|}
\hline Study & Study design & $\begin{array}{l}\text { Cases/cohort size } \\
\text { or controls }\end{array}$ & Gender & Age & Source population & Involved risk factors \\
\hline Voigt et al, $1994^{34}$ & Case-control & $349 / 1457$ & Female & $18-64$ & $\begin{array}{l}\text { Group Health Cooperative } \\
\text { of Puget Sound }\end{array}$ & $\begin{array}{l}\text { Smoking, BMI, alcohol } \\
\text { drinking }\end{array}$ \\
\hline $\begin{array}{l}\text { Criswell et al, } \\
2002^{36}\end{array}$ & Cohort & $158 / 31336$ & Female & $55-69$ & lowa Women's Health Study & Smoking \\
\hline $\begin{array}{l}\text { Krishnan et al, } \\
2003^{37}\end{array}$ & Case-control & $644 / 1509$ & $\begin{array}{l}\text { Male and } \\
\text { female }\end{array}$ & 25-NA & $\begin{array}{l}\text { Behavioural risk factor } \\
\text { surveillance system }\end{array}$ & Smoking \\
\hline $\begin{array}{l}\text { Mikuls et al, } \\
2010^{38}\end{array}$ & Case-control & $605 / 255$ & $\begin{array}{l}\text { Male and } \\
\text { female }\end{array}$ & NA & $\begin{array}{l}\text { Consortium for the } \\
\text { Longitudinal } \\
\text { Evaluations of African } \\
\text { Americans with Early } \\
\text { Rheumatoid Arthritis }\end{array}$ & Smoking \\
\hline \multirow[t]{2}{*}{ Lu et al, $2014^{44}$} & \multirow[t]{2}{*}{ Cohort } & $826 / 109896$ & Female & $30-55$ & Nurses' Health Study & \multirow[t]{2}{*}{ BMI } \\
\hline & & $355 / 108727$ & Female & $25-42$ & Nurses' Health Study II & \\
\hline \multirow[t]{2}{*}{ Lu et al, $2014^{45}$} & \multirow[t]{2}{*}{ Cohort } & $580 / 82472$ & Female & $30-55$ & Nurses' Health Study & \multirow[t]{2}{*}{ Alcohol drinking } \\
\hline & & $323 / 110737$ & Female & $25-42$ & Nurses' Health Study II & \\
\hline $\begin{array}{l}\text { Lamichhane et al, } \\
2018^{40}\end{array}$ & Cohort & $185 / 76668$ & Female & $50-79$ & $\begin{array}{l}\text { Women's Health Initiative } \\
\text { Observational Study }\end{array}$ & $\begin{array}{l}\text { Smoking, BMI, alcohol } \\
\text { drinking }\end{array}$ \\
\hline \multirow[t]{2}{*}{ Liu et al, $2019^{41}$} & \multirow[t]{2}{*}{ Cohort } & $1002 / 117182$ & Female & $30-55$ & Nurses' Health Study & \multirow[t]{2}{*}{ Smoking } \\
\hline & & $526 / 113550$ & Female & $25-42$ & Nurses' Health Study II & \\
\hline Parks et al, $2019^{42}$ & Cohort & $478 / 49406$ & $\begin{array}{l}\text { Male and } \\
\text { female }\end{array}$ & NA & $\begin{array}{l}\text { Individuals in Agricultural } \\
\text { Health Study and their } \\
\text { spouses }\end{array}$ & Smoking \\
\hline
\end{tabular}

BMI, body mass index; NA, not applicable; RA, rheumatoid arthritis.

Q test $^{30}$ and $\mathrm{I}^{2}$ statistic, ${ }^{31}$ with a statistically significant heterogeneity defined as $\mathrm{p}<0.10$ or $\mathrm{I}^{2}>50 \%$. A randomeffects mode ${ }^{32}$ was applied when a statistically significant value was presented; otherwise the fixed-effects model ${ }^{33}$ was used. Sensitivity analysis was performed to evaluate the stability of the association by sequential removal of each study from the analysis. Publication bias was assessed using Egger's test and Begg's test. A funnel plot was generated, of which symmetry suggested no evidence of publication bias. The Preferred Reporting Items for Systematic Reviews and Meta-Analyses checklist for reporting systematic reviews and meta-analyses was used.

Statistical tests were performed using SAS V.9.2 software (SAS) and STATA V.12.0 software (StataCorp). A p $<0.05$ was considered significant.

\section{Patient and public involvement}

Patients or the public were not involved in the design, conduct, reporting or dissemination of our research.

\section{RESULTS}

\section{Distribution of risk factors}

Of the 6437 individuals aged more than 15 years sampled for NHANES 2005-2006, the total percentages of never smokers, former smokers and current smokers were $52.79 \%, 25.32 \%$ and $21.90 \%$ (table 1). For BMI, the percentages of overweight and obesity were $23.44 \%$ and $22.93 \%$, respectively. The average alcohol consumption was $3.57 \mathrm{drink} /$ week, approximately equal to $44.63 \mathrm{~g} /$ week. Table 1 also presents the weighted proportion of smoking status, and the weighted means of BMI and alcohol consumption, which were used for PAF calculation in subsequent analysis. If a lag-time of 15 years instead of 10 years between the selected risk factors and risk of RA was considered, we used NHANES 2001-2002 dataset for sensitivity analysis, and the corresponding result was shown in table 1.

\section{Association between selected risk factors and RA}

The flow chart of study inclusion and exclusion was shown in online supplemental figure 1 . Nine studies ${ }^{34-42}$ were included to evaluate the association between smoking status and risk of RA among US adults, among which there were five cohort studies, three case-control studies and one nested case-control study (table 2). Four studies had a score of 8 , three studies scored 7 and two study scored 6 , respectively (online supplemental table 2). Compared with never smokers, former smokers $\left(\mathrm{I}^{2}=57.4 \%, \mathrm{RR}=1.22\right.$, 


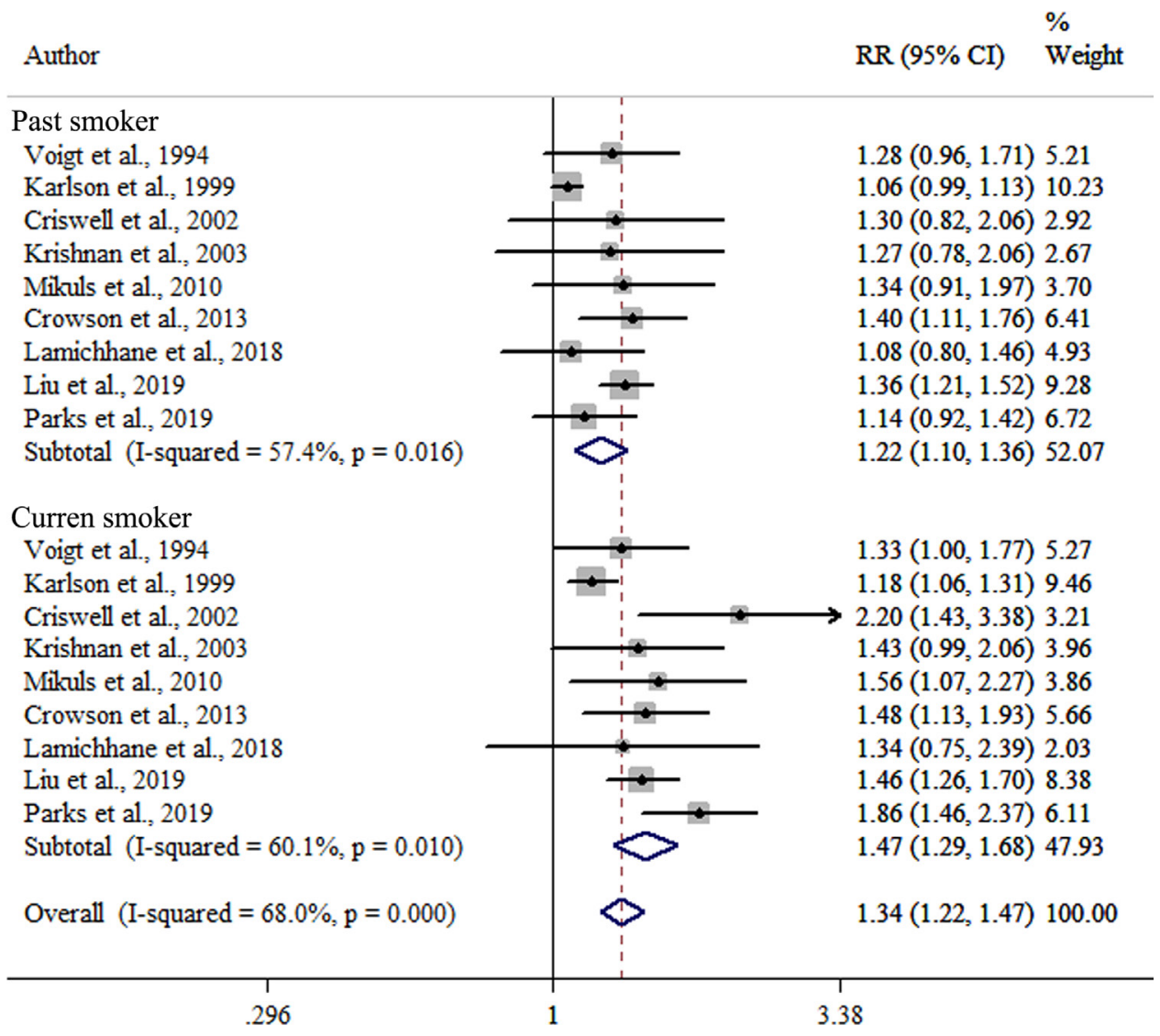

Figure 1 Forest plot of the association between smoking and risk of RA. RA, rheumatoid arthritis; RR, relative risk.

$95 \%$ CI 1.10 to 1.36$)$ and current smokers $\left(\mathrm{I}^{2}=60.1 \%\right.$, $\mathrm{RR}=1.47,95 \%$ CI 1.29 to 1.68$)$ in the meta-analysis (figure 1). In sensitivity analysis, omission of one study at a time did not materially alter the results, with RR ranging from 1.05 to 1.41 in former smoking and from 1.24 to 1.75 in current smoking, respectively. The Begg's test ( $p=0.917$ for past smoking; $p=0.917$ for current smoking) and Egger's test ( $p=0.174$ for past smoking; $p=0.062$ for current smoking) did not suggest evidence of potential publication bias.

Four studies ${ }^{3404344}$ reported the association between BMI and risk of RA, including three cohort studies and one case-control study (table 2). One study had a score of 8 , two studies scored 7 and one study scored 6 , respectively (online supplemental table 2). The linear regression model indicated a high goodness of fit for the risk of RA, with the RR of 1.09 (95\% CI 1.04 to 1.15) for every 5 $\mathrm{kg} / \mathrm{m}^{2}$ increase in BMI. In the categorical meta-analysis, excess BMI was found to be higher risk of $\mathrm{RA}\left(\mathrm{I}^{2}=44.0 \%\right.$, $\mathrm{RR}=1.27$, 95\% CI 1.09 to 1.48 ; figure 2 ). Sensitivity analysis suggested that RRs ranged from 0.92 to 1.70 , as the study by $\mathrm{Lu} e t a l^{44}$ had a strong effect on the combined effect estimates. The Begg's test $(\mathrm{p}=1.000)$ and Egger's test $(p=0.772)$ did not suggest evidence of potential publication bias.

Likewise, a total of four studies ${ }^{3404345}$ were included in the dose-response meta-analysis of the association between alcohol consumption and risk of RA among US adults (table 2). There were three cohort studies and one case-control study. Two studies scored 8 and two study scored 7 , respectively (online supplemental table 2). As no evidence of a non-linear relationship was found $\left(\mathrm{p}_{\text {non-linearity }}=0.321\right)$, we used linear model to assess the association between alcohol consumption and risk of RA (figure 3). The linear dose-response relationship was statistically significant for RA (RR (95\% CI) per $50 \mathrm{~g}$ / week increment: $0.92(0.84$ to 1.00$))$ with low heterogeneity $(\mathrm{p}=0.690)$. Sensitivity analysis and publication bias test were not available in the dose-response meta-analysis.

\section{PAFs of selected risk factors}

The estimated PAFs were summarised in table 3. Smoking was one of the main RA risk factors in US adults with a PAF of $14.00 \%$ (95\% CI $8.13 \%$ to $23.33 \%$ ), with an estimation of 16072 attributable RA incident cases. Excess BMI accounted for $14.73 \%$ (95\% CI $5.45 \%$ to $23.50 \%$ ) of RA risk (16 910 cases). The fraction of RA risk attributed by alcohol intake was $8.21 \%$ (95\% CI $0.31 \%$ to $16.39 \%$ ), with the estimated cases of 9425 . Overall, we estimated that $32.69 \%$ (95\% CI $13.41 \%$ to $50.96 \%$ ) of the total incident RA cases in 2016 were attributable to the combined effects of smoking, high BMI and no alcohol drinking.

In sensitivity analysis, the proportion of RA risk attributable to smoking, high BMI and no alcohol intake would be $14.14 \%$ (95\% CI $8.28 \%$ to $23.44 \%$ ), $14.38 \%$ (95\% CI $5.30 \%$ to $22.99 \%$ ) and $9.49 \%$ (95\% CI $0.36 \%$ to $18.82 \%$ ), respectively. Collectively, the above three risk factors 


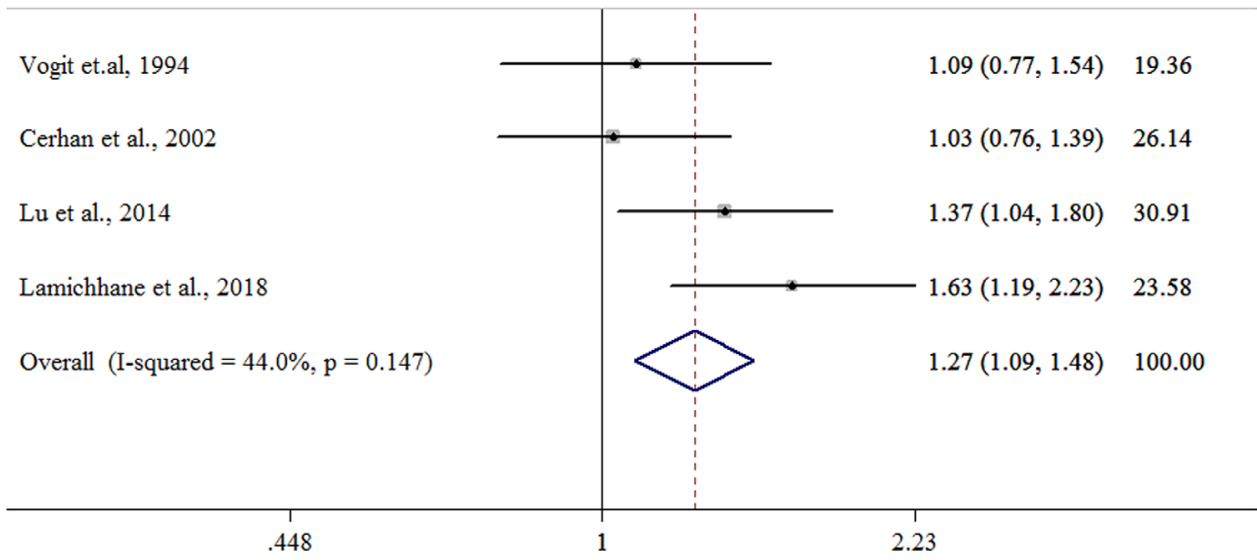

Figure 2 Forest plot of the association between overweight/obesity and risk of RA. RA, rheumatoid arthritis; RR, relative risk.

contributed to $33.46 \%$ (95\% CI $13.45 \%$ to $52.14 \%$ ) of RA cases.

\section{DISCUSSION}

This study comprehensively estimates the burden of RA incidence attributable to well known risk factors among US adults. Overall, we estimated that $32.69 \%$ of RA incident cases were attributable to the combined effect of smoking, excess BMI and no alcohol intake. Smoking and excess BMI accounted for the most fraction of RA incidence, and the robustness of PAF with respect to different lag-time was confirmed by sensitivity analysis.

Smoking is by far the most recognised risk factor for RA. The biological effect of smoking in the risk of RA was found to interact with human leukocyte antigen-DRB1 shared epitope (HLA-DRB1 SE) alleles in triggering and persuading immunity against citrullinated proteins. ${ }^{46}$ In our meta-analysis for previous epidemiological studies conducted in US adults, we found consistent association between smoking and risk of RA, with pooled RRs of 1.22 in former smokers and 1.47 in current smokers, although we found modest heterogeneity. The complexity of participant characteristics may possibly explain the difference, for example, reproductive factors among female participants, while most of these variables were not available for subgroup analysis and meta-regression analysis. The magnitude of PAF value $(14.00 \%)$ between smoking and RA is similar to, or smaller than, those in three previous

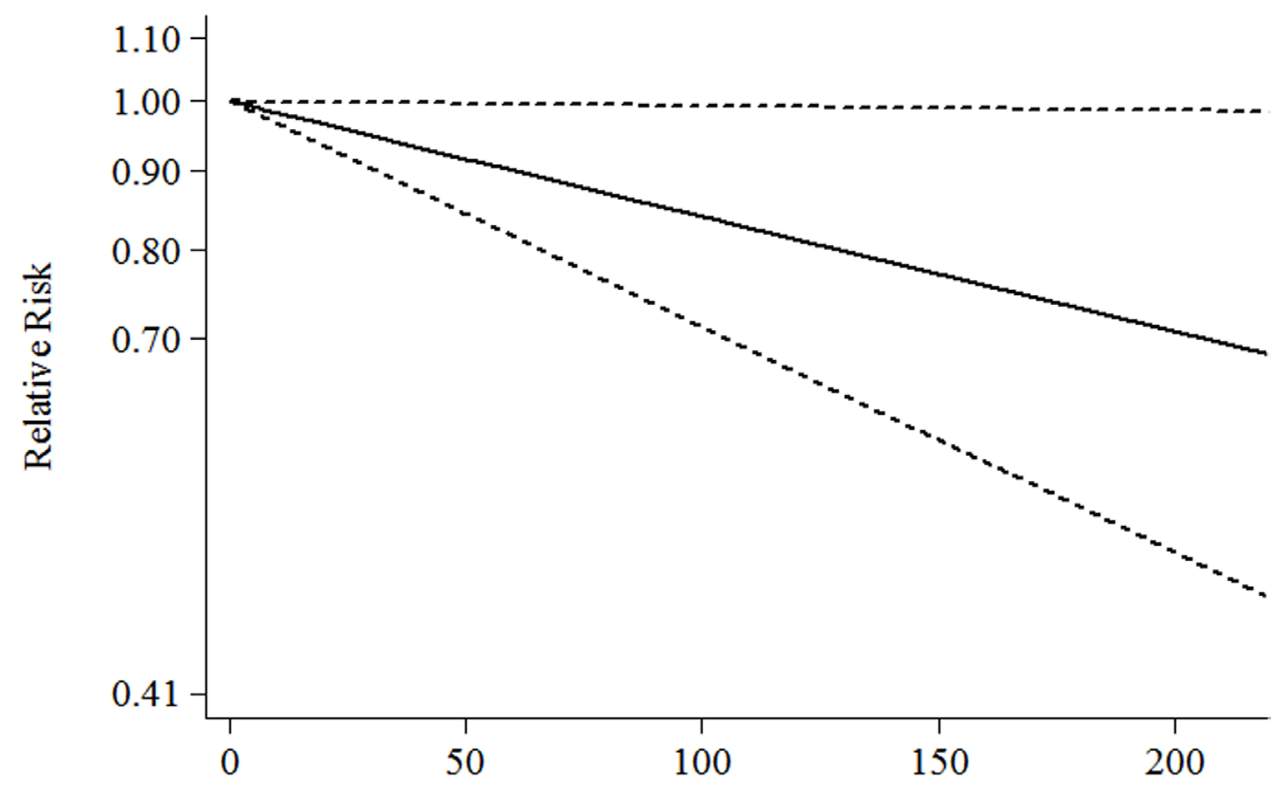

Alcohol intake, grams/week

Figure 3 Dose-response relationship between alcohol consumption and risk of RA. RA, rheumatoid arthritis. 
Table 3 Number and proportion of RA cases attributable to selected risk factors in USA (2016), aged more than 15 years

\begin{tabular}{lrr}
\hline & PAF (95\% Cl) & Cases \\
\hline Smoking & $14.00 \%(8.13 \%$ to $23.33 \%)$ & 16072 \\
Excess BMI & $14.73 \%(5.45 \%$ to $23.50 \%)$ & 16910 \\
Alcohol drinking & $8.21 \%(0.31 \%$ to $16.39 \%)$ & 9425 \\
Total & $32.69 \%(13.41 \%$ to $50.96 \%)$ & 37528 \\
\hline
\end{tabular}

BMI, body mass index; PAF, population attributable fraction; RA, rheumatoid arthritis.

studies of US women. For example, among 65457 women with sufficient data of familial RA or lupus in the Nurses' Health Study, smoking more than 10 pack-years was found to account for $14 \%$ of RA risk. ${ }^{47}$ It is estimated that smoking contributes $18 \%$ and $25 \%$ of the populationattributable risk of RA in Iowa Women's Health Study ${ }^{36}$ and Nurses' Health Study. ${ }^{48}$ The discrepancy may mainly due to that our RR estimation was based on meta-analysis from original studies among both men and women, which was more stable and comprehensive than one single study.

Although high BMI is a less established RA risk factor than smoking, there is growing interest in understanding the association between excess weight and disease risk, as the prevalence of overweight and obesity is increasing worldwide at an alarming rate. ${ }^{49}$ Adipocytes present in overweight and obese individuals have been shown to secrete inflammatory markers, ${ }^{50}$ including tumour necrosis factor- $\alpha$ and interleukin- 6 , which have been implicated in RA pathogenesis. In our meta-analysis, categorical and continuous BMI were both found to be associated with increased risk of RA. The PAF value of overweight and obesity on RA reached $14.73 \%$, and the result of sensitivity analysis for estimating PAF using the prevalence in 2001 remained robust. Our estimation was higher than Sparks's study, ${ }^{47}$ which could be explained by the source of prevalence of overweight and obesity.

Previous studies found that low to moderate level of alcohol consumption was inversely and significantly associated with the development of RA in a dose-respondent manner. ${ }^{6}$ The mechanism behind this association may be that alcohol could downregulate the immune response and decrease production of proinflammatory cytokines. ${ }^{49}$ In the current dose-response meta-analysis, a decreased risk of RA was found with an RR of 0.92 for every $50 \mathrm{~g} /$ week increase in alcohol consumption. Moreover, the fraction of RA risk attributed by no alcohol intake was $8.21 \%$. Only one similar study was available in USA, ${ }^{47}$ and showed that low alcohol intake (none or $<5 \mathrm{~g} /$ day) accounted for $12 \%$ of RA risk. Thus, more research is needed to elucidate the burden of alcohol consumption on risk of RA among US adults.

In terms of actionable prevention for RA, currently there is likely enough evidence to recommend that to reduce risks for RA that individuals should stop smoking and maintain optimal body weight. The decision of whether alcohol drinking is beneficial becomes a trade-off, because it might increase the proportion of heavy drinkers and thereby enhance the risk of other diseases such as strokes, some cancers, cirrhosis of the liver or injuries. But at least that moderate drinking will not increase risk of RA.

The main strength of our study was the systematic assessment of RA causes among US adults, which integrated prevalence data from nationally representative studies with meta-analysis on the association between selected risk factors and risk of RA. However, our results have several limitations, because there were several sources of uncertainty in the PAF estimates. First, RA incidence was lacking, and was estimated from mortality data using IMR. Limited by the available IMR estimation near the year of 2016, the current study used the IMR value estimated by pooling seven cohorts after the year of 1983 from a previous meta-analysis published in $2013{ }^{15}$ For the downward trend in IMR over time, as the availability of new treatments such as methotrexate and biological disease-modifying antirheumatic drugs, introduced huge benefits for the treatment of RA and these drugs are associated with survival benefits, the outdated IMR value from previous study may result in underestimation of RA incidence. Second, several other known risk factors of RA exist but have not been included in our study. For example, further emerging evidence suggests that diet might be associated with risk of RA, but the results were inconsistent. Third, we cannot exclude the possibility of residual confounding on account of the nature of the included observational studies in the metaanalysis, although most of the studies adjusted for major risk factors of RA. Fourth, we estimated the PAF value under the assumption that there would be no change in the lifestyle factors over time, which is often unrealistic. Fifthly, we did not adjust the PAFs for the potential interaction of the selected risk factors (eg, the joint effects of smoking and alcohol drinking), because few data from USA can be available to provide the accurate RRs for interaction between these risk factors. Combined PAF for the three risk factors, however, was estimated in our study. Furthermore, as PAF value can vary from one population to another because of the impact of other risk factors and the interaction with environmental and genetics factors, the PAF calculation in the current study was estimated among US adults, confining its representativeness.

\section{CONCLUSION}

We estimated RA incident cases attributable to smoking, overweight or obesity and alcohol drinking, informing key intervention targets to reduce RA risk in the region. The effect of unselected risk factors on RA is still unknown. It is needed to continue more fundamental research on other lifestyle factors to illuminate the questions.

Contributors CW and DY conceived the study. DY, YM, CW and ZX designed the study. YX and XX conducted the systematic review and meta-analysis. DY and 
YM conducted the PAF analysis. DY and YM drafted the manuscript, and all of the coauthors contributed to critical revision of the manuscript. The corresponding authors attest that all listed coauthors meet authorship criteria and that no others meeting the criteria have been omitted. All authors interpreted the data, critically revised the manuscript for important intellectual content, and approved the final version of the manuscript.

Funding This work was supported by grants of National Key R\&D Program of China (2018YFC1705500) and National Natural Science Foundation of China (81973663).

Disclaimer The funders had no role in the study design, data analysis, interpretation of data, or preparation of the manuscript.

Competing interests None declared.

Patient consent for publication Not required.

Provenance and peer review Not commissioned; externally peer reviewed.

Data availability statement All data relevant to the study are included in the article or uploaded as online supplemental information.

Supplemental material This content has been supplied by the author(s). It has not been vetted by BMJ Publishing Group Limited (BMJ) and may not have been peer-reviewed. Any opinions or recommendations discussed are solely those of the author(s) and are not endorsed by BMJ. BMJ disclaims all liability and responsibility arising from any reliance placed on the content. Where the content includes any translated material, BMJ does not warrant the accuracy and reliability of the translations (including but not limited to local regulations, clinical guidelines, terminology, drug names and drug dosages), and is not responsible for any error and/or omissions arising from translation and adaptation or otherwise.

Open access This is an open access article distributed in accordance with the Creative Commons Attribution Non Commercial (CC BY-NC 4.0) license, which permits others to distribute, remix, adapt, build upon this work non-commercially, and license their derivative works on different terms, provided the original work is properly cited, appropriate credit is given, any changes made indicated, and the use is non-commercial. See: http://creativecommons.org/licenses/by-nc/4.0/.

ORCID iD

Ding Ye http://orcid.org/0000-0001-6654-7832

\section{REFERENCES}

1 Mclnnes IB, Schett G. Pathogenetic insights from the treatment of rheumatoid arthritis. The Lancet 2017;389:2328-37.

2 van der Woude D, van der Helm-van Mil AHM. Update on the epidemiology, risk factors, and disease outcomes of rheumatoid arthritis. Best Pract Res Clin Rheumatol 2018;32:174-87.

3 Alamanos Y, Voulgari PV, Drosos AA. Incidence and prevalence of rheumatoid arthritis, based on the 1987 American College of rheumatology criteria: a systematic review. Semin Arthritis Rheum 2006;36:182-8

4 Smolen JS, Aletaha D, Mclnnes IB. Rheumatoid arthritis. The Lancet 2016;388:2023-38.

5 Di Giuseppe D, Discacciati A, Orsini N, et al. Cigarette smoking and risk of rheumatoid arthritis: a dose-response meta-analysis. Arthritis Res Ther 2014;16:R61.

6 Jin Z, Xiang C, Cai Q, et al. Alcohol consumption as a preventive factor for developing rheumatoid arthritis: a dose-response metaanalysis of prospective studies. Ann Rheum Dis 2014;73:1962-7.

7 Lee YH, Bae S-C, Song GG. Coffee or tea consumption and the risk of rheumatoid arthritis: a meta-analysis. Clin Rheumatol 2014;33:1575-83.

8 Di Giuseppe D, Crippa A, Orsini N, et al. Fish consumption and risk of rheumatoid arthritis: a dose-response meta-analysis. Arthritis Res Ther 2014;16:446.

9 Viatte S, Plant D, Raychaudhuri S. Genetics and epigenetics of rheumatoid arthritis. Nat Rev Rheumatol 2013;9:141-53.

10 Mansournia MA, Altman DG. Population attributable fraction. BMJ 2018:360:k757

11 Källberg H, Ding B, Padyukov L, et al. Smoking is a major preventable risk factor for rheumatoid arthritis: estimations of risks after various exposures to cigarette smoke. Ann Rheum Dis 2011;70:508-11.

12 Ezzati M, Vander Hoorn S, Rodgers A, et al. Estimates of global and regional potentil health gains from reducing muliple major risk factors. The Lancet 2003;362:271-80.

13 Global Health Estimates. 2016: Deaths by cause, age, sex, by country and by region, 2000-2016. Geneva: World Health Organization, 2018.
14 WHO methods and data sources for country-level causes of death 2000-2016. Global health estimates technical paper WHO/HIS/ IER/GHE/2018.3. Geneva: World Health Organization, 2018. http:// terrance.who.int/mediacentre/data/ghe/GlobalCOD method 2000 2016.pdf?ua $=1$

15 Dadoun S, Zeboulon-Ktorza N, Combescure C, et al. Mortality in rheumatoid arthritis over the last fifty years: systematic review and meta-analysis. Joint Bone Spine 2013;80:29-33.

16 Collaborators G. Global, regional, and national comparative risk assessment of 84 behavioural, environmental and occupational, and metabolic risks or clusters of risks for 195 countries and territories, 1990-2017: a systematic analysis for the global burden of disease study 2017. Lancet 2018;392:1923-94.

17 About the National Health and Nutrition Examination Survey:Introduction.CDC. Available: http://www.cdc.gov/nchs/ nhanes/about_nhanes.htm

18 Health topic data guide: smoking status. Centers for disease control and Prevention.Disability and health data system. Available: http:// dhds.cdc.gov/guides/healthtopics/indicator? $\mathrm{i}=$ smokingstatus [Accessed 6 February, 2013].

19 Flegal KM. The effects of changes in smoking prevalence on obesity prevalence in the United States. Am J Public Health 2007;97:1510-4.

20 Tsai J, Ford ES, Li C, et al. Past and current alcohol consumption patterns and elevations in serum hepatic enzymes among US adults. Addict Behav 2012;37:78-84.

21 Hamling J, Lee P, Weitkunat R, et al. Facilitating meta-analyses by deriving relative effect and precision estimates for alternative comparisons from a set of estimates presented by exposure level or disease category. Stat Med 2008;27:954-70.

22 Greenland S, Longnecker MP. Methods for trend estimation from summarized dose-response data, with applications to meta-analysis. Am J Epidemiol 1992;135:1301-9.

23 Stang A. Critical evaluation of the Newcastle-Ottawa scale for the assessment of the quality of nonrandomized studies in metaanalyses. Eur J Epidemiol 2010;25:603-5.

24 Fedirko V, Tramacere I, Bagnardi V, et al. Alcohol drinking and colorectal cancer risk: an overall and dose-response meta-analysis of published studies. Annals of Oncology 2011;22:1958-72.

25 Orsini N, Li R, Wolk A, et al. Meta-Analysis for linear and nonlinear dose-response relations: examples, an evaluation of approximations, and software. Am J Epidemiol 2012;175:66-73.

26 Berlin JA, Longnecker MP, Greenland S. Meta-Analysis of epidemiologic dose-response data. Epidemiology 1993;4:218-28.

27 Levin ML. The occurrence of lung cancer in man. Acta Unio Int Contra Cancrum 1953;9:531-41.

28 MJ G, Huang QC, Bao CZ, et al. Attributable causes of colorectal cancer in China. BMC Cancer 2018;18:38.

29 Wang JB, Jiang $\mathrm{Y}$, Liang $\mathrm{H}$, et al. Attributable causes of cancer in China. Annals of Oncology 2012;23:2983-9.

30 Higgins JPT, Thompson SG. Quantifying heterogeneity in a metaanalysis. Stat Med 2002;21:1539-58.

31 Higgins JPTet al. Measuring inconsistency in meta-analyses. BMJ 2003;327:557-60.

32 DerSimonian R, Laird N. Meta-Analysis in clinical trials. Control Clin Trials 1986;7:177-88.

33 Greenland S. Quantitative methods in the review of epidemiologic LITERATURE1. Epidemiol Rev 1987;9:1-30.

34 Voigt LF, Koepsell TD, Nelson JL, et al. Smoking, obesity, alcohol consumption, and the risk of rheumatoid arthritis. Epidemiology 1994:5:525-32.

35 Karlson EW, Lee I-M, Cook NR, et al. A retrospective cohort study of cigarette smoking and risk of rheumatoid arthritis in female health professionals. Arthritis \& Rheumatism 1999;42:910-7.

36 Criswell LA, Merlino LA, Cerhan JR, et al. Cigarette smoking and the risk of rheumatoid arthritis among postmenopausal women: results from the lowa Women's Health Study. Am J Med 2002;112:465-71.

37 Smoking KE. Gender and rheumatoid arthritis-epidemiological clues to etiology. results from the behavioral risk factor surveillance system. Joint Bone Spine 2003;70:496-502.

38 Mikuls TR, Sayles H, Yu F, et al. Associations of cigarette smoking with rheumatoid arthritis in African Americans. Arthritis \& Rheumatism 2010;62:3560-8.

39 Crowson CS, Matteson EL, Davis JM, et al. Contribution of obesity to the rise in incidence of rheumatoid arthritis. Arthritis Care Res 2013:65:71-7.

40 Lamichhane D, Collins C, Constantinescu F, et al. Coffee and tea consumption in relation to risk of rheumatoid arthritis in the Women's health Initiative observational cohort. JCR: Journal of Clinical Rheumatology 2019;25:127-32.

41 Liu X, Tedeschi SK, Barbhaiya M, et al. Impact and Timing of Smoking Cessation on Reducing Risk of Rheumatoid Arthritis 
Among Women in the Nurses' Health Studies. Arthritis Care Res 2019;71:914-24.

42 Parks CG, Meyer A, Beane Freeman LE, et al. Farming tasks and the development of rheumatoid arthritis in the agricultural health study. Occup Environ Med 2019;76:243-9.

43 Cerhan JR, Saag KG, Criswell LA, et al. Blood transfusion, alcohol use, and anthropometric risk factors for rheumatoid arthritis in older women. J Rheumatol 2002;29:246-54.

44 Lu B, Hiraki LT, Sparks JA, et al. Being overweight or obese and risk of developing rheumatoid arthritis among women: a prospective cohort study. Ann Rheum Dis 2014;73:1914-22.

$45 \mathrm{Lu} \mathrm{B}$, Solomon DH, Costenbader KH, et al. Alcohol consumption and risk of incident rheumatoid arthritis in women: a prospective study. Arthritis \& Rheumatology 2014;66:1998-2005.

46 Klareskog L, Stolt P, Lundberg K, et al. A new model for an etiology of rheumatoid arthritis: Smoking may trigger HLA-DR (shared epitope)-restricted immune reactions to autoantigens modified by citrullination. Arthritis Rheum 2006;54:38-46.

47 Sparks JA, Chen C-Y, Hiraki LT, et al. Contributions of familial rheumatoid arthritis or lupus and environmental factors to risk of rheumatoid arthritis in women: a prospective cohort study. Arthritis Care Res 2014;66:1438-46.

48 Costenbader KH, Feskanich D, Mandl LA, et al. Smoking intensity, duration, and cessation, and the risk of rheumatoid arthritis in women. Am J Med 2006;119:503.e1-503.e9.

49 Zaccardelli A, Friedlander HM, Ford JA, et al. Potential of lifestyle changes for reducing the risk of developing rheumatoid arthritis: is an ounce of prevention worth a pound of cure? Clin Ther 2019;41:1323-45.

50 Panagiotakos D, Pitsavos C, Yannakoulia M, et al. The implication of obesity and central fat on markers of chronic inflammation: the Attica study. Atherosclerosis 2005;183:308-15. 